\begin{tabular}{|c|l|}
\hline Title & $\begin{array}{l}\text { Structural and mutational analyses of the receptor binding domain of botulinum D C mosaic neurotoxin : Insight into } \\
\text { the ganglioside binding mechanism }\end{array}$ \\
\hline Author(s) & $\begin{array}{l}\text { Nuemket, Nipawan; T anaka, Y oshikazu; T sukamoto, Kentaro; T suji, Takao; Nakamura, Keiji; Kozaki, Shunji; Y ao, } \\
\text { Min; Tanaka, Isao }\end{array}$ \\
\hline Citation & $\begin{array}{l}\text { Biochemical and Biophysical Research Communications, 411(2), 433-439 } \\
\text { https://doi.org/40.1016/.bbrc.2011.06.173 }\end{array}$ \\
\hline Issue Date & 2011-07-29 \\
\hline Doc URL & http://hdl.handle.net/2115/47078 \\
\hline Type & article (author version) \\
\hline File Information & BBRC411-2_433-439.pdf \\
\hline
\end{tabular}

Instructions for use 


\section{Structural and Mutational Analyses of the Receptor Binding Domain of Botulinum D/C Mosaic Neurotoxin: Insight into the Ganglioside Binding Mechanism}

Nipawan Nuemket ${ }^{1}$, Yoshikazu Tanaka ${ }^{2,3}$, Kentaro Tsukamoto ${ }^{4}$, Takao Tsuji ${ }^{4}$, Keiji Nakamura $^{5}$, Shunji Kozaki ${ }^{5}$, Min Yao ${ }^{1,3}$, and Isao Tanaka ${ }^{1,3^{*}}$

1 Graduate School of Life Sciences, Hokkaido University, Sapporo 060-0810, Japan

2 Creative Research Institution “Sousei," Hokkaido University, Sapporo 001-0021, Japan

3 Faculty of Advanced Life Science, Hokkaido University, Sapporo 060-0810, Japan

4 Department of Microbiology, Fujita Health University School of Medicine, Toyoake, Aichi 470-1192, Japan

5 Department of Veterinary Science, Graduate School of Life and Environmental Sciences, Osaka Prefecture University, Osaka 598-8531, Japan

* Corresponding author; e-mail: tanaka@castor.sci.hokudai.ac.jp; Tel.: +81-11-706-3221; Fax: +81-11-706-4905 


\begin{abstract}
Clostridium botulinum type D strain OFD05, which produces the $\mathrm{D} / \mathrm{C}$ mosaic neurotoxin, was isolated from cattle killed by the recent botulism outbreak in Japan. The $\mathrm{D} / \mathrm{C}$ mosaic neurotoxin is the most toxic of the botulinum neurotoxins (BoNT) characterized to date. Here, we determined the crystal structure of the receptor binding domain of BoNT from strain OFD05 in complex with 3'-sialyllactose at a resolution of 3.0A. In the structure, an electron density derived from the 3'-sialyllactose was confirmed at the cleft in the C-terminal subdomain. Alanine site-directed mutagenesis showed the significant contribution of the residues surrounding the cleft to ganglioside recognition. In addition, a loop adjoining the cleft also plays an important role in ganglioside recognition. In contrast, little effect was observed when the residues located around the surface previously identified as the protein receptor binding site in other BoNTs were substituted. The results of cell binding analysis of the mutants were significantly correlated with the ganglioside binding properties. Based on these observations, a cell binding mechanism of BoNT from strain OFD05 is proposed, which involves cooperative contribution of two ganglioside binding sites.
\end{abstract}

\title{
Keywords
}

botulinum neurotoxin, $\mathrm{D} / \mathrm{C}$ mosaic, receptor binding domain, crystal structure, ganglioside recognition 


\section{Introduction}

From recent outbreaks of botulism in cattle farms in Japan, Clostridium botulinum strain OFD05 was isolated from feces specimens [1]. It produces a DC mosaic botulinum neurotoxin (BoNTs). Genetic analysis of the toxin showed that it consists of two thirds of type D neurotoxin (BoNT/D) and one third of type C neurotoxin $(\mathrm{BoNT} / \mathrm{C})[1,2]$. Moreover, it showed the highest lethality in mice following intraperitoneal injection $\left(1.1 \times 10^{9} \mathrm{LD}_{50} / \mathrm{mg}\right.$ protein) compared with other types of BoNT. Structurally, the activated mature toxin consists of three functionally distinct modules: the light chain with $\mathrm{Zn}^{2+}$-dependent metalloprotease activity and the heavy chain that encompasses the $\mathrm{N}$-terminal 50-kDa translocation domain $\left(\mathrm{H}_{\mathrm{N}}\right)$, and $\mathrm{C}$-terminal 50-kDa receptor binding domain $\left(\mathrm{H}_{\mathrm{C}}\right)[3,4,5]$. These modules work cooperatively to ensure successful intoxication to the target presynaptic neuron cell. A two-receptor model has been proposed as the initial binding step using the $\mathrm{H}_{\mathrm{C}}$ domain of BoNTs, in which the $\mathrm{H}_{\mathrm{C}}$ domain recognizes both ganglioside and protein receptor $[6,7,8]$. These complex structures of BoNT_H $\mathrm{H}_{\mathrm{C}}$ and its receptors revealed that BoNTs use a structurally conserved site, i.e., the ganglioside binding site (GBS), to recognize ganglioside, in which the peptide motif SXWY is conserved among the majority of BoNTs examined to date [4,9]. For the protein receptor, the structure of BoNT/B was determined in the complex form with synaptotagmin-II (Syt-II) (PDBID 2NM1), which showed that the protein binding site (PBS) lies next to the ganglioside binding site (GBS) separated by a loop region [10]. Based on these structures, a model in which ganglioside and protein receptor are recognized individually at GBS and PBS, respectively, was proposed for the two-receptor model $[9,10]$.

There have been some interesting recent reports regarding BoNTs that cause animal botulism, i.e., type $\mathrm{C}$, type $\mathrm{D}$, and the $\mathrm{D} / \mathrm{C}$ mosaic type. Strotmeier et al. reported that both GBS and PBS are used for ganglioside binding in type D lacking the SXWY motif [11]. In addition, Karalewitz et al. reported that a loop located between PBS and GBS (the ganglioside binding loop, GBL) contributes markedly to ganglioside recognition by type $\mathrm{C}$, which also lacks the SXWY motif [12]. However, there have been no previous reports regarding these BoNTs in which the functions of each site, i.e., the PBS, GBS, and the loop between them, were evaluated by an identical method. In the present study, we compared the contributions of these regions in the $\mathrm{H}_{\mathrm{C}}$ domain of BoNT from strain OFD05 $\left(\mathrm{OFD} 05 \mathrm{H}_{\mathrm{C}}\right)$ on ganglioside and cell binding. First, we obtained crystal structures of $\mathrm{OFD} 05 \mathrm{H}_{\mathrm{C}}$ in apo and complex forms with 3'-sialyllactose, which defined GBS, PBS, and GBL. Then, we constructed alanine-substituted mutants based on the crystal structure, and evaluated ganglioside binding by SPR and P19 cell 
binding assay. Based on the results, we propose a receptor binding mechanism of OFD $05 \mathrm{H}_{\mathrm{C}}$, which utilizes ganglioside as its receptor at the classical GBS with auxiliary contributions from GBL. 


\section{Materials and Methods}

Expression, purification, and crystallization

\subsection{Preparation and crystallization of $\mathrm{OFD} 05 \mathrm{H}_{C}$}

Expression and purification of $\mathrm{OFD} 05 \mathrm{H}_{\mathrm{C}}$ (residues E859-E1285) were described previously [13]. The crystals of $\mathrm{OFD} 05 \mathrm{H}_{\mathrm{C}}$ that were used for further X-ray diffraction analysis were grown with $100 \mathrm{mM}$ MES (pH 6.5) and 1.6 M magnesium sulfate.

\subsection{Crystallization of OFD05H $\mathrm{H}_{C}$ in complex with 3'-sialyllactose}

The expression vector was prepared with a KOD-Plus Mutagenesis Kit (Toyobo, Osaka, Japan) using synthesized primers (Supplementary Table 1) and plasmid constructed previously [13]. The later steps including expression and purification were conducted using the same procedures as described previously [13]. After concentrating protein to 3 $\mathrm{mg} / \mathrm{ml}$, 3'-sialyllactose (Sigma-Aldrich, St. Louis, MO) was added at a final concentration of $5 \mathrm{mM}$. The mixture was incubated at $293 \mathrm{~K}$ for at least $30 \mathrm{~min}$, and then used for crystallization. The best crystal of $\mathrm{OFD} 05 \mathrm{H}_{\mathrm{C}}$ in complex with 3'-sialyllactose was grown from a mother liquor containing $100 \mathrm{mM}$ MES (pH 6.5), 1.6 $\mathrm{M}$ magnesium sulfate, and $1 \mathrm{M}$ sodium chloride.

\section{Data collection and structure determination}

X-ray diffraction data were collected at the synchrotron facilities of Spring-8 (Hyogo, Japan) and Photon Factory (Tsukuba, Japan).

$\mathrm{X}$-ray diffraction data of $\mathrm{OFD} 05 \mathrm{H}_{\mathrm{C}}$ and in complex with 3'-sialyllactose were collected at resolutions of 3.1 and $2.99 \AA$, respectively (Table 1). Diffraction data were processed, integrated, and scaled using the programs HLK2000 [14] and XDS [15]. The crystal structures were determined by the molecular replacement method with the program MOLREP [16] in the CCP4 program package [17] using the structure of BoNT/D-South Africa $\mathrm{H}_{\mathrm{C}}$ (PDB ID 3N7L) as a search model. The model was constructed manually using the program COOT [18]. Positional and B-factor refinement were carried out with the programs REFMAC5 [19] and Phenix [20,21]. Finally, 836 residues (from two molecules) and 27 water molecules were placed in the structure of $\mathrm{OFD} 05 \mathrm{H}_{\mathrm{C}}$ with crystallographic $\mathrm{R}$ and $\mathrm{R}_{\text {free }}$ values of $24.4 \%$ and $28.9 \%$, respectively. For $\mathrm{OFD} 05 \mathrm{H}_{\mathrm{C}}$ in complex with 3'-sialyllactose, 836 residues and 12 water molecules could be constructed with $\mathrm{R}$ and $\mathrm{R}_{\text {free }}$ values of $25.0 \%$ and $29.2 \%$, respectively.

\section{Preparation of mutants}

Site-directed mutants were constructed by QuikChange site-directed mutagenesis (Stratagene, La Jolla, CA). The primers used for construction of the mutants are listed in 
Supplementary Table 1. These mutants were induced for heterogeneous protein expression in Escherichia coli under the same conditions as the wild-type $\mathrm{OFD} 5 \mathrm{H}_{\mathrm{C}}$ [13]. After cell disruption, the supernatant was purified by a Ni-NTA agarose column (Qiagen, Germantown, MD). Fractions containing the target protein were collected and dialyzed against $20 \mathrm{mM}$ Tris- $\mathrm{HCl}(\mathrm{pH} \mathrm{8.0)}$ and $200 \mathrm{mM} \mathrm{NaCl}$.

\section{Surface Plasmon Resonance}

POPC (1-palmitoyl-2-oleoyl-sn-glycero-3-phosphocholine) $(5 \mu \mathrm{mol})$ in chloroform was mixed with 1 mol\% ganglioside GM1a, GDla, and GQ1b from bovine brain in chloroform/methanol mixture (1:1 by volume) and dried to a thin film under nitrogen gas using an evaporator. The lipid film was hydrated with addition of $0.5 \mathrm{~mL}$ of phosphate buffered saline by vortexing for 3 min to yield $10 \mathrm{mM}$ solution with respect to POPC. After freeze-thawing five times, the suspension was extruded 20 times through a $50 \mathrm{nM}$ filter. As a negative control, liposomes were also prepared from POPC alone. Immobilization of liposomes on the L1 sensor chip (GE Healthcare, Waukesha, WI, USA) and all measurements of SPR were performed using a Biacore 2000 (GE Healthcare). The immobilized sensor chip was primed with $10 \mathrm{mM}$ HBS-N. Each analyte $\left(\mathrm{OFD} 05 \mathrm{H}_{\mathrm{C}}\right.$ and its mutants, $\left.500 \mathrm{nM}\right)$ in HBS-N was injected for 2 min at a flow rate of $30 \mu \mathrm{L} / \mathrm{min}$. After dissociation with the same buffer for $2 \mathrm{~min}$, the chip was regenerated with a 1-min injection of $1 \mathrm{mM} \mathrm{NaOH}$ to remove the residual $\mathrm{H}_{\mathrm{C}}$ on the surface and then replaced with HBS-N for use in subsequent cycles. The sensorgram of the binding of POPC alone was subtracted from that of POPC containing ganglioside as nonspecific binding.

\section{Fluorescence Immunocytochemistry}

P19 embryonal carcinoma cells were kindly provided by Dr. T. Ohkawara (Mie University, Mie, Japan). The cells were cultured and induced to differentiate into neuronal cells using the procedures described previously [22,23]. The cells were treated with or without $50 \mathrm{nM} \mathrm{H}_{\mathrm{C}}$ for $30 \mathrm{~min}$ at $37^{\circ} \mathrm{C}$, and washed three times with $1 \mathrm{~mL}$ of culture medium. The cells were fixed in $4 \%$ paraformaldehyde/phosphate buffered saline for $15 \mathrm{~min}$ at room temperature. The fixed cells were permeabilized with phosphate buffered saline containing $0.1 \%$ Triton X-100 for $5 \mathrm{~min}$ at room temperature. After three rinses with phosphate buffered saline containing $10 \mathrm{mM}$ glycine, the cultures were incubated with phosphate buffered saline containing 3\% bovine serum albumin (BSA). For detection of intracellular $\mathrm{H}_{\mathrm{C}}$, the cells were incubated with rabbit polyclonal anti-OFD $05 \mathrm{H}_{\mathrm{C}}$ antibody $(5 \mu \mathrm{g} / \mathrm{mL})$ for $30 \mathrm{~min}$ at room temperature. After 
washing with phosphate buffered saline $-0.1 \%$ BSA, the cells were incubated with Alexa Fluor ${ }^{\circledR}$ 488-conjugated anti-rabbit IgG (1:500) (Invitrogen) for $30 \mathrm{~min}$ at room temperature. After washing with phosphate buffered saline $-0.1 \% \mathrm{BSA}$, the cells were mounted on slide glasses with ProLong ${ }^{\circledR}$ Gold Antifade reagent (Invitrogen). Immunoreactive cells were visualized under an LSM 710 confocal microscope (Zeiss, Oberkochen, Germany). Fluorescence intensity was measured with ZEN2009 software (Zeiss). 


\section{Results}

Crystal structure of OFD05H $H_{C}$ in complex with 3'-sialyllactose

The crystal structure of $\mathrm{OFD}^{2} \mathrm{H}_{\mathrm{C}}$ in the presence of $3^{\prime}$-sialyllactose $(\alpha$-NeuNAc- $(2 \rightarrow 3)-\beta$-D-Gal- $(1 \rightarrow 4)-D-G l c)$ was determined by the molecular replacement method at a resolution of $2.99 \AA$ (Fig. 1A). Based on structure comparison with BoNT/A in complex with GT1b and BoNT/B with Syt-II, the ganglioside binding site (GBS), the protein receptor binding site (PBS), and a long ganglioside binding loop (GBL) were defined (Fig. 1A and 1D). In one of two molecules contained in an asymmetric unit, a substantial electron density was observed in the GBS surrounded by N1114, I1240, G1241, Y1243, and L1270 (Fig. 1B). In contrast, no electron density was found at the corresponding site of the other molecule. The structural superposition of BoNT/A - GT1b complex showed that the electron density overlapped onto the GT1b in the structure of BoNT/A (Fig. 1C), suggesting that the observed electron density corresponds to bound 3'-siallyllactose. However, we could not construct a model of 3'-sialyllactose, as the observed electron density was too small and ambiguous. In addition, a sulfate ion was bound at the tip of the GBL, with which F1251, W1252, Y1253, and H1255 made interactions.

To confirm that the observed electron density was derived from 3'-sialyllactose, crystals of apo form OFD05 $\mathrm{H}_{\mathrm{C}}$ was prepared under similar conditions in which MES buffer and magnesium sulfate were used, and the structure was determined at a resolution of $3.1 \AA$. No electron density was observed around the GBS, although the structures of OFD05 $\mathrm{H}_{\mathrm{C}}$ were quite similar (RMSD 0.29 and $0.62 \AA$ over $418 \mathrm{C} \alpha$ atoms for two molecules in an asymmetric unit, respectively). These results confirmed that the electron density observed in the complex structure was derived from 3'-sialyllactose. The side chains as well as the main chains around GBS of the apo and complex forms were superposed well, suggesting that no major structural changes occurred after binding with 3'-sialyllactose. In the structure of the complex with 3'-sialyllactose, a sulfate ion was bound at the tip of the GBL.

\section{Mutation analysis for ganglioside binding}

The crystal structure of $\mathrm{OFD} 05 \mathrm{H}_{\mathrm{C}}$ in complex with 3 '-sialyllactose showed that OFD05H $\mathrm{H}_{\mathrm{C}}$ captures sugar parts of ganglioside at the GBS. In addition, a unique ganglioside binding mechanism using the GBL located between GBS and the PBS was proposed for the $\mathrm{H}_{\mathrm{C}}$ region of BoNT/C. In addition, Strotmeier et al. recently reported that in the BoNT/D, the PBS as well as GBS acts as the ganglioside recognition site [11]. In the case of BoNT/C or BoNT/DC, however, the contributions of these individual 
regions to receptor binding have not been compared with each other. To evaluate them, 23 alanine-substituted mutants were prepared and their ganglioside binding activities were evaluated by surface plasmon resonance (SPR). The constructed mutants were categorized into three groups: i.e., mutations around GBS, GBL, and PBS.

Ten mutants with mutations around GBS were prepared, and we examined the binding of three types of ganglioside (Supplementary Fig 1A and 2). In all mutants, significant decrease in the binding activity was observed statistically. G1241A, N1114A, I1240A, L1270A, Y1243A, and L1190A showed marked decreases in activity (Fig 2). Even in other mutants, i.e., S1269A, K1263A, and S1242A, the SPR signal was decreased to approximately $60 \%$ of that in the wild-type. It should be noted that mutation of residues located adjacent to the electron density in the structure of $\mathrm{OFD} 05 \mathrm{H}_{\mathrm{C}}-3$ 'syalyllactose complex, i.e., G1241A, N1114A, I1240A, Y1243A, and L1270, caused significant decreases in the activity (Fig. 1B). These results indicated that GBS in $\mathrm{OFD}_{0} 5 \mathrm{H}_{\mathrm{C}}$ contributes strongly to ganglioside binding similar to other BoNTs. Similar tendencies were confirmed for all types of ganglioside examined (GM1a, GQ1b, GD1a) (Fig. 2), although the degree of decrease in the activity for GQ1b was smaller than the others.

For mutations in GBL, three alanine-substituted mutants of the residues located at the tip of the loop, F1251A, W1252A, and F1253A, were constructed (Supplementary Fig 1B). In addition, a mutant in which the loop region from Ser1244 to Glu1256 was replaced by two glycine residues $\left(\mathrm{ODF} 05 \mathrm{H}_{\mathrm{C}}-\Delta \mathrm{loop}\right)$ was prepared. In all of these mutants, marked decreases in binding activity for all types of ganglioside were observed (Fig. 2, which are all statistically significant), although 3'-sialyllactose was not found around this region in the crystal structure. Instead, a sulfate ion was found at the GBL position in both crystal structures.

As mutations in PBS, ten residues were mutated based on the structural alignment between OFD05H $\mathrm{H}_{\mathrm{C}}$ and BoNT/B - Syt-II (Supplementary Fig. 1C and 3), which are the structural counterparts of the residues of BoNT/B that interact with Syt-II. SPR analyses indicated that all of the alanine substituted mutants showed binding activity for all types of ganglioside, although those of G1124A, G1126A, and P1192 were approximately half those of the wild-type (Fig. 2). Although all mutants other than Y1175A showed statistical difference, the effects of substitutions of PBL are obviously weaker than those for GBS and/or GBL. These results indicated that $\mathrm{OFD} 05 \mathrm{H}_{\mathrm{C}}$ does not recognize ganglioside with PBL.

P19 cell binding activity of the mutants

Crystal structure and SPR analysis showed that $\mathrm{OFD}_{0} 5 \mathrm{H}_{\mathrm{C}}$ recognizes ganglioside using 
GBS and GBL, but PBL does not contribute strongly. To explore the contributions of these regions to ganglioside binding in vivo, the binding of each mutant for P19 cells was evaluated (Fig. 3).

All mutants of GBL showed markedly reduced cell binding activity, suggesting the importance of this region for cell binding as well as ganglioside recognition. In addition, mutants in GBS, with the exception of S1242A, K1263A, S1269A, and S1273, showed remarkable decreases in the cell binding activity. It should be noted that similar results were also obtained in SPR analysis. In contrast, the activities of the mutants for PBS other than P1192A were comparable to that of wild-type, which also showed a significant correlation with the results of SPR. P1192A showed a fluorescent signal that was approximately $60 \%$ of wild-type. Taken together, all mutants that showed a significant decrease in ganglioside binding activity in SPR also showed a marked decrease in cell binding. Therefore, we concluded that the results of cell binding assay are strongly correlated with those of ganglioside binding activity as determined by SPR. 


\section{Discussion}

The crystal structure of OFD $05 \mathrm{H}_{\mathrm{C}}$ in the presence of 3'-sialyllactose showed substantial electron density around GBS, although the model of 3'-sialyllactose could not be constructed due to its incomplete shape. The electron density was not observed in the reference crystal of $\mathrm{OFD} 05 \mathrm{H}_{\mathrm{C}}$, which did not contain 3'-sialyllactose. In addition, substitution of the residues located around the electron density markedly diminished the ganglioside binding activity (N1114A, I1240A, G1241A, Y1243A, and L1270A in Fig. 2). In particular, the inactivation of N1114A was the most significant among the constructed mutants. Moreover, the effect was observed for all types of ganglioside examined, whereas other mutants showed only residual activity for GQ1b. Based on these observations, we concluded that the electron density was derived from the 3'-sialyllactose, and the GBS in $\mathrm{OFD}_{0} 5 \mathrm{H}_{\mathrm{C}}$ recognizes the sugar part of gangliosides similar manner to other BoNTs. It should be noted that the SXWY motif is not conserved in the GBS of OFD05H $\mathrm{H}_{\mathrm{C}}$, unlike other BoNTs. Although the absence of the motif in the GBS was also reported for BoNT/D, it has ganglioside binding properties distinct from $\mathrm{OFD} 05 \mathrm{H}_{\mathrm{C}}$, in which both GBS and PBS are present.

Mutations of the GBL resulted in marked inactivation of binding for all types of ganglioside, as well as P19 cells, indicating the importance of the GBL. Karalewitz et al. also recently reported the contribution of W1252 located at the tip of the GBL to ganglioside binding [12]. Our results showed that not only W1252, but also the adjacent residues and the entire loop region are also important for receptor binding. Although the mutation in GBL strongly affected the binding of all gangliosides, there was no electron density of 3'-sialyllactose around the GBL. The GBL thus appears to recognize a part that is not contained in the 3'-sialyllactose but is common to all gangliosides, such as the hydrophilic part of ceramide. Interestingly, sulfate was found at the GBL regardless of the conditions used for crystal growth. The sulfate ion was also bound in the same site of BoNT/D, and therefore it was proposed that this loop was bound to the negatively charged phospholipid membrane surface [24]. However, our results excluded this hypothesis for $\mathrm{OFD} 05 \mathrm{H}_{\mathrm{C}}$, because a significant signal was not found in the reference flow cell in the SPR experiment in which the lipid bilayer is immobilized. If the GBL can bind with the hydrophilic head group of the phospholipid membrane surface, a binding signal should be observed in the reference cell. As described above, the GBS is likely to bind directly to the ganglioside. The distance between the electron density of 3 '-sialyllactose and the tip of the loop is approximately $30 \AA$. The GBL would come close to the GBS to form a ganglioside binding site, when $\mathrm{OFD} 05 \mathrm{H}_{\mathrm{C}}$ recognizes ganglioside. As substitution into either GBS or GBL resulted in a marked decrease in 
ganglioside binding, these two regions are likely to act in a cooperative manner. However, in the case of GQ1b binding, weak activity was observed for mutants of the GBS, instead of the marked inactivation in the mutants of GBL. The contribution of the GBL may be more significant than that of GBS. In contrast to the GBS and GBL, the effects of mutations in the PBS did not cause serious inactivation of binding with either ganglioside or P19 cell, although slight decrease was observed in several mutants such as G1124A, G1126A, P1192A and I1259A. As PBS and GBS are located back to back, these mutants may affect structural flexibility and/or integrity of the GBS. Taken together, we concluded that $\mathrm{OFD} 05 \mathrm{H}_{\mathrm{C}}$ recognizes gangliosides using the GBS and GBL, and that the PBS does not make a major contribution.

The results of SPR and P19 cell binding assay were correlated strongly with each other. That is, mutants that showed a significant decrease in ganglioside binding activity on SPR analysis also showed a marked decrease in cell binding, and those with ganglioside binding activity in SPR also had cell binding activity. These results indicated that ganglioside recognition governs binding to the cell. Moreover, the GBS and GBL of OFD $05 \mathrm{H}_{\mathrm{C}}$ contributed to ganglioside recognition in a cooperative manner, which is a unique property of BoNT/C. In other BoNTs with the exception of BoNT/D, gangliosides are recognized only by GBS, and PBS is responsible for binding to the protein receptor $[9,10,25,26,27]$. In BoNT/D, both GBS and PBS recognize gangliosides [11]. Moreover, the function of GBL has not been reported for other BoNTs. As mentioned above, BoNT/C and BoNT/D do not possess the SXWY motif and have unique ganglioside binding properties, whereas other BoNTs possessing the SXWY motif capture gangliosides using only GBS. BoNT/C may have developed the ganglioside binding mechanism to overcome the absence of the SXWY motif, and thus have obtained a unique cell binding mechanism in which both GBS and GBL are used for ganglioside recognition.

\section{Acknowledgments}

We thank Mr. K. Yamashita of Hokkaido University for help with structure analysis. This work was supported by Grants-in-Aid from the Ministry of Education, Science, Sports, and Culture of Japan (Y. T.).

\section{Figure legends}

Figure 1. Crystal structure of the $\mathrm{H}_{\mathrm{C}}$ or BoNT from OFD05 strain in complex with 3'-sialyllactose. (A) Ribbon and surface model. The N- and C-terminal subdomains 
$\left(\mathrm{H}_{\mathrm{CN}}\right.$ and $\mathrm{H}_{\mathrm{CC}}$, respectively), ganglioside binding side (GBS), ganglioside binding loop (GBL), and protein binding site (PBS) are indicated. (B) Ribbon diagram around the GBS. The Fo\# $\#$ map corresponding to the 3'-sialyllactose is also shown. The residues located around this map are also indicated. (C) GBS of BoNT/A $\mathrm{H}_{\mathrm{C}}$. Eight crucial residues for BoNT/A and GT1b recognition are shown. (D) Superposition with $\mathrm{H}_{\mathrm{C}}$ of BoNT/A (blue), BoNT/B (magenta), and OFD05 $\mathrm{H}_{\mathrm{C}}$ (green). Bound GT1b at the GBS of BoNT/A and synaptotagmin-II (Syt-II) at the PBS of BoNT/B are also shown as cyan sticks and red ribbon model, respectively. The direction is identical to that of Fig. 1A (left).

Figure 2. SPR analysis of the interactions between OFD05 $\mathrm{H}_{\mathrm{C}}$ and GM1a (A), GD1a (B), and GQ1b (C). The results for wild-type (WT) are also shown. The bars represent the average of resonance unit (RU) from triplicate injections of analyte, and the standard errors are indicated by error bars. Statistical analyses were performed by ANOVA using GraphPad Prism software, and the significant difference was determined using one-way ANOVA with Dunnett post-hoc test. Asterisks indicate the significant differences from the result of WT. (*, $\left.\mathrm{P}<0.05 ;{ }^{* *}, \mathrm{P}<0.01 ;{ }^{* * *}, \mathrm{P}<0.0001\right)$.

Figure 3. Binding activities of $\mathrm{OFD05H}_{\mathrm{C}}$ mutants against $\mathbf{P 1 9}$ cells. The results of wild-type (WT) and negative control $\left(\mathrm{H}_{\mathrm{C}^{-}}\right)$are also shown. The dashed line indicates baseline fluorescence intensity of the negative control. The bars represent the average of fluorescence intensity from three random regions, and the standard errors are indicated by error bars. Asterisks indicate the significant differences from the result of WT. $\left(^{*}\right.$, $\mathrm{P}<0.05 ; * *, \mathrm{P}<0.01 ; * * *, \mathrm{P}<0.0001)$.

\section{References}

[1] K. Nakamura, T. Kohda, K. Umeda, H. Yamamoto, M. Mukamoto, S. Kozaki, Characterization of the $\mathrm{D} / \mathrm{C}$ mosaic neurotoxin produced by Clostridium botulinum associated with bovine botulism in Japan, Vet Microbiol 140 (2010) 147-154.

[2] K. Moriishi, M. Koura, N. Abe, N. Fujii, Y. Fujinaga, K. Inoue, K. Ogumad, Mosaic structures of neurotoxins produced from Clostridium botulinum types $\mathrm{C}$ and $\mathrm{D}$ 
organisms, Biochim Biophys Acta 1307 (1996) 123-126.

[3] D.B. Lacy, W. Tepp, A.C. Cohen, B.R. DasGupta, R.C. Stevens, Crystal structure of botulinum neurotoxin type A and implications for toxicity, Nat Struct Biol 5 (1998) 898-902.

[4] S. Swaminathan, S. Eswaramoorthy, Structural analysis of the catalytic and binding sites of Clostridium botulinum neurotoxin B, Nat Struct Biol 7 (2000) 693-699.

[5] D.B. Lacy, R.C. Stevens, Sequence homology and structural analysis of the clostridial neurotoxins, J Mol Biol 291 (1999) 1091-1104.

[6] A. Rummel, K. Hafner, S. Mahrhold, N. Darashchonak, M. Holt, R. Jahn, S. Beermann, T. Karnath, H. Bigalke, T. Binz, Botulinum neurotoxins C, E and F bind gangliosides via a conserved binding site prior to stimulation-dependent uptake with botulinum neurotoxin F utilising the three isoforms of SV2 as second receptor, J Neurochem 110 (2009) 1942-1954.

[7] A. Rummel, T. Karnath, T. Henke, H. Bigalke, T. Binz, Synaptotagmins I and II act as nerve cell receptors for botulinum neurotoxin G, J Biol Chem 279 (2004) 30865-30870.

[8] A.K. Singh, S.H. Harrison, J.S. Schoeniger, Gangliosides as receptors for biological toxins: development of sensitive fluoroimmunoassays using ganglioside-bearing liposomes, Anal Chem 72 (2000) 6019-6024.

[9] P. Stenmark, J. Dupuy, A. Imamura, M. Kiso, R.C. Stevens, Crystal structure of botulinum neurotoxin type $\mathrm{A}$ in complex with the cell surface co-receptor GT1b-insight into the toxin-neuron interaction, PLoS Pathog 4 (2008) e1000129.

[10] R. Jin, A. Rummel, T. Binz, A.T. Brunger, Botulinum neurotoxin B recognizes its protein receptor with high affinity and specificity, Nature 444 (2006) 1092-1095.

[11] J. Strotmeier, K. Lee, A.K. Volker, S. Mahrhold, Y. Zong, J. Zeiser, J. Zhou, A. Pich, H. Bigalke, T. Binz, A. Rummel, R. Jin, Botulinum neurotoxin serotype D attacks neurons via two carbohydrate-binding sites in a ganglioside-dependent manner, Biochem J 431 (2010) 207-216.

[12] A.P. Karalewitz, A.R. Kroken, Z. Fu, M.R. Baldwin, J.J. Kim, J.T. Barbieri, Identification of a unique ganglioside binding loop within botulinum neurotoxins C and D-SA, Biochemistry 49 (2010) 8117-8126.

[13] N. Nuemket, Y. Tanaka, K. Tsukamoto, T. Tsuji, K. Nakamura, S. Kozaki, M. Yao, I. Tanaka, Preliminary X-ray crystallographic study of the receptor-binding domain of the $\mathrm{D} / \mathrm{C}$ mosaic neurotoxin from Clostridium botulinum, Acta Crystallogr Sect F Struct Biol Cryst Commun 66 (2010) 608-610. 
[14] Z. Otwinowski, W. Minor, Processing of X-ray diffraction data collected in oscillation mode, 1997.

[15] W. Kabsch, Xds, Acta Crystallogr D Biol Crystallogr 66 (2010) 125-132.

[16] A. Vagin, A. Teplyakov, Molecular replacement with MOLREP, Acta Crystallogr D Biol Crystallogr 66 (2010) 22-25.

[17] N. Collaborative Computational Project, The CCP4 suite: programs for protein crystallography, Acta Crystallogr D Biol Crystallogr 50 (1994) 760-763.

[18] P. Emsley, K. Cowtan, Coot: model-building tools for molecular graphics, Acta Crystallogr D Biol Crystallogr 60 (2004) 2126-2132.

[19] G.N. Murshudov, P. Skubak, A.A. Lebedev, N.S. Pannu, R.A. Steiner, R.A. Nicholls, M.D. Winn, F. Long, A.A. Vagin, REFMAC5 for the refinement of macromolecular crystal structures, Acta Crystallogr D Biol Crystallogr 67 (2011) 355-367.

[20] P.D. Adams, R.W. Grosse-Kunstleve, L.W. Hung, T.R. Ioerger, A.J. McCoy, N.W. Moriarty, R.J. Read, J.C. Sacchettini, N.K. Sauter, T.C. Terwilliger, PHENIX: building new software for automated crystallographic structure determination, Acta Crystallogr D Biol Crystallogr 58 (2002) 1948-1954.

[21] P.H. Zwart, P.V. Afonine, R.W. Grosse-Kunstleve, L.W. Hung, T.R. Ioerger, A.J. McCoy, E. McKee, N.W. Moriarty, R.J. Read, J.C. Sacchettini, N.K. Sauter, L.C. Storoni, T.C. Terwilliger, P.D. Adams, Automated structure solution with the PHENIX suite, Methods Mol Biol 426 (2008) 419-435.

[22] M.W. McBurney, E.M. Jones-Villeneuve, M.K. Edwards, P.J. Anderson, Control of muscle and neuronal differentiation in a cultured embryonal carcinoma cell line, Nature 299 (1982) 165-167.

[23] M.W. McBurney, K.R. Reuhl, A.I. Ally, S. Nasipuri, J.C. Bell, J. Craig, Differentiation and maturation of embryonal carcinoma-derived neurons in cell culture, J Neurosci 8 (1988) 1063-1073.

[24] Y. Zhang, G.W. Buchko, L. Qin, H. Robinson, S.M. Varnum, Crystal structure of the receptor binding domain of the botulinum C-D mosaic neurotoxin reveals potential roles of lysines 1118 and 1136 in membrane interactions, Biochem Biophys Res Commun 404 (2011) 407-412.

[25] Q. Chai, J.W. Arndt, M. Dong, W.H. Tepp, E.A. Johnson, E.R. Chapman, R.C. Stevens, Structural basis of cell surface receptor recognition by botulinum neurotoxin B, Nature 444 (2006) 1096-1100.

[26] D. Kumaran, S. Eswaramoorthy, W. Furey, J. Navaza, M. Sax, S. Swaminathan, Domain organization in Clostridium botulinum neurotoxin type $\mathrm{E}$ is unique: its 
implication in faster translocation, J Mol Biol 386 (2009) 233-245.

[27] C. Chen, Z. Fu, J.J. Kim, J.T. Barbieri, M.R. Baldwin, Gangliosides as high affinity receptors for tetanus neurotoxin, J Biol Chem 284 (2009) 26569-26577. 
Table 1. Crystallographic statistics

\begin{tabular}{|c|c|c|}
\hline & Apo (SeMet) & Complex \\
\hline PDB code & $3 \mathrm{AZV}$ & $3 \mathrm{AZW}$ \\
\hline \multicolumn{3}{|l|}{ Data collection } \\
\hline Beamline & SPring-8 BL41XU & Photon Factory BL5A \\
\hline Wavelength $(\AA)$ & 0.977 & 1.0000 \\
\hline Space group & $P 2_{1} 2_{1} 2_{1}$ & $P 2_{1} 2_{1} 2_{1}$ \\
\hline \multicolumn{3}{|l|}{ Cell } \\
\hline $\operatorname{dimensions}\left(\AA,^{\circ}\right)$ & $a=58.0, b=138.6, c=162.6$ & $a=58.0, b=141.6, \mathrm{c}=162.0$ \\
\hline Resolution range & $45.0-3.10(3.27-3.10)$ & $45.0-2.99(3.15-2.99)$ \\
\hline$R_{\text {sym }}(\%)$ & $12.9(84.0)$ & $12.6(92.8)$ \\
\hline$<I / \sigma(I)>$ & $10.5(2.57)$ & $13.7(2.69)$ \\
\hline Completeness (\%) & $99.4(99.9)$ & $99.3(95.6)$ \\
\hline Multiplicity & $4.96(5.04)$ & $8.09(8.08)$ \\
\hline \multicolumn{3}{|l|}{ No. of observed } \\
\hline reflections & $226,365(34,275)$ & $223,512(30,512)$ \\
\hline \multicolumn{3}{|l|}{ No. of unique } \\
\hline reflections & $45,646(6,802)$ & $27,614(3,778)$ \\
\hline \multicolumn{3}{|l|}{ Refinement } \\
\hline$R$-work (\%) & 24.4 & 25.0 \\
\hline$R$-free $(\%)$ & 28.9 & 29.2 \\
\hline \multicolumn{3}{|l|}{ No. of protein } \\
\hline atoms & 6,852 & 6,852 \\
\hline No. of ligand atoms & 10 & 10 \\
\hline \multicolumn{3}{|l|}{ No of water } \\
\hline molecules & 27 & 12 \\
\hline \multicolumn{3}{|l|}{ rms from ideal } \\
\hline bond lengths $(\AA)$ & 0.0072 & 0.0084 \\
\hline bond angles $\left({ }^{\circ}\right)$ & 0.97 & 1.0 \\
\hline \multicolumn{3}{|l|}{ Ramachandran plot } \\
\hline Favored (\%) & 92.3 & 92.8 \\
\hline Allowed (\%) & 7.70 & 7.20 \\
\hline Outliers (\%) & 0.00 & 0.00 \\
\hline
\end{tabular}


Supplementary Table 1 . Primer sequences

\begin{tabular}{|c|c|}
\hline Primer & Sequence $\left(5^{\prime} \rightarrow 3^{\prime}\right)$ \\
\hline $\mathrm{f}-5 \mathrm{~N} \Delta \mathrm{OFD} 05 \mathrm{H}_{\mathrm{C}}$ & ATTAATGAATATTTCAATAGTATTAATGATTCAAAAATTTTG \\
\hline $\mathrm{r}-5 \mathrm{~N} \Delta \mathrm{OFD} 05 \mathrm{H}_{\mathrm{C}}$ & ATGGTATATCTCCTTCTTAAAGTTAAAC \\
\hline \multicolumn{2}{|l|}{ GBS Mutants } \\
\hline f-N1114A & TGATTAACGTAGCGTATATGAATAGATA \\
\hline $\mathrm{r}-\mathrm{N} 1114 \mathrm{~A}$ & CTATTCATATACGCTACGTTAATCATGT \\
\hline f-L1190A & TAGGGACTGATGCGGTTCCACTAGGTGC \\
\hline r-L1190A & CCTAGTGGAACCGCATCAGTCCCTAGAT \\
\hline f-I1240A & GGAATACTATCAGCGGGTAGTTATAGTTTC \\
\hline r-I1240A & ACTATAACTACCCGCTGATAGTATTCCAAG \\
\hline $\mathrm{f}-\mathrm{G} 1241 \mathrm{~A}$ & ATACTATCAATTGCGAGTTATAGTTTCAAAC \\
\hline $\mathrm{r}-\mathrm{G} 1241 \mathrm{~A}$ & TGAAACTATAACTCGCAATTGATAGTATTCC \\
\hline $\mathrm{f}-\mathrm{S} 1242 \mathrm{~A}$ & TACTATCAATTGGTGCGTATAGTTTCAAACTTGG \\
\hline $\mathrm{r}-\mathrm{S} 1242 \mathrm{~A}$ & AGTTTGAAACTATACGCACCAATTGATAGTATTC \\
\hline$f-Y 1243 A$ & CAATTGGTAGTGCGAGTTTCAAACTTGG \\
\hline $\mathrm{r}-\mathrm{Y} 1243 \mathrm{~A}$ & AGTTTGAAACTCGCACTACCAATTGATA \\
\hline$f-K 1263 A$ & TTCCTGTTATAGCGATAGAGCATTATGC \\
\hline $\mathrm{r}-\mathrm{K} 1263 \mathrm{~A}$ & TAATGCTCTATCGCTATAACAGGAATTA \\
\hline f-S1269A & AGCATTATGCTGCGTTATTAGAATCAAC \\
\hline $\mathrm{r}-\mathrm{S} 1269 \mathrm{~A}$ & GATTCTAATAACGCAGCATAATGCTCTA \\
\hline f-L1270A & ATTATGCTTCAGCGTTAGAATCAACATC \\
\hline r-L1270A & GTTGATTCTAACGCTGAAGCATAATGCT \\
\hline f-S1273A & CATTATTAGAAGCGACATCAACTCATTG \\
\hline $\mathrm{r}-\mathrm{S} 1273 \mathrm{~A}$ & TGAGTTGATGTCGCTTCTAATAATGAAG \\
\hline \multicolumn{2}{|l|}{ GBL } \\
\hline$f-Y 1251 A$ & GGAGATGACGCTTGGTTTAATCACG \\
\hline $\mathrm{r}-\mathrm{Y} 1251 \mathrm{~A}$ & GATTAAACCAAGCGTCATC TCCAAG \\
\hline$f-W 1252 A$ & GATGACTATGCGTTTAATCACG \\
\hline $\mathrm{r}-\mathrm{W} 1252 \mathrm{~A}$ & TGATTAAACGCATAGTCATCTC \\
\hline $\mathrm{f}-\mathrm{F} 1253 \mathrm{~A}$ & GACTATTGGGCAAATCACGAATATTTAATTC \\
\hline $\mathrm{r}-\mathrm{F} 1253 \mathrm{~A}$ & TTAAATATTCGTGATTTGCCCAATAGTCATC \\
\hline f-del_loop & GGTTATTTAATTCCTGTTATAAAAATAGAGCATTATGCTTC \\
\hline r-del_loop & ACCATAACTACCAATTGATAGTATTCCAAGCCTATTTG \\
\hline
\end{tabular}


PBS

f-G1124A GTCTAAAAAAGCGAATGGAATTGTTTTT

r-G1124A ACAATTCCATTCGCTTTTTTAGACATAT

f-G1126A AAAAGGCAATGCGATTGTTTTTAATACACG

r-G1126A TTAAAAACAATCGCATTGCCTTTTTTAGAC

f-Y1175A ATAACAAACAAGCGAGTTTAGGTATGTAT

r-Y1175A ATACCTAAACTCGCTTGTTTGTTATCAAT

f-M1179A ATAGTTTAGGTGCGTATAAACCTTCTAG

r-M1179A AAGGTTTATACGCACCTAAACTATATTG

f-V1191A TGATTTAGCGCCACTAGGTGC

r-V1191A CCTAGTGGCGCTAAATCAGTC

f-P1192A CTGATTTAGTTGCGCTAGGTGCATTGG

r-P1192A TGCACCTAGCGCAACTAAATCAGTC

f-L1196A TAGGTGCAGCGGATCAACCAATG

r-L1196A GTTGATCCGCTGCACCTAGTGG

f-D1197A GCATTGGCGCAACCAATGGATG

r-D1197A CCATTGGTTGCGCCAATGCACC

f-Y1206A AGATACGTAAAGCGGGTTCGTTTATAATAC

r-Y1206A ATAAACGAACCCGCTTTACGTATCTCATCC

f-I1259A ACGAATATTTAGCGCCTGTTATAAAAATA

r-I1259A TTTATAACAGGCGCTAAATATTCGTGATTA 
Figure 1

Figure 1A
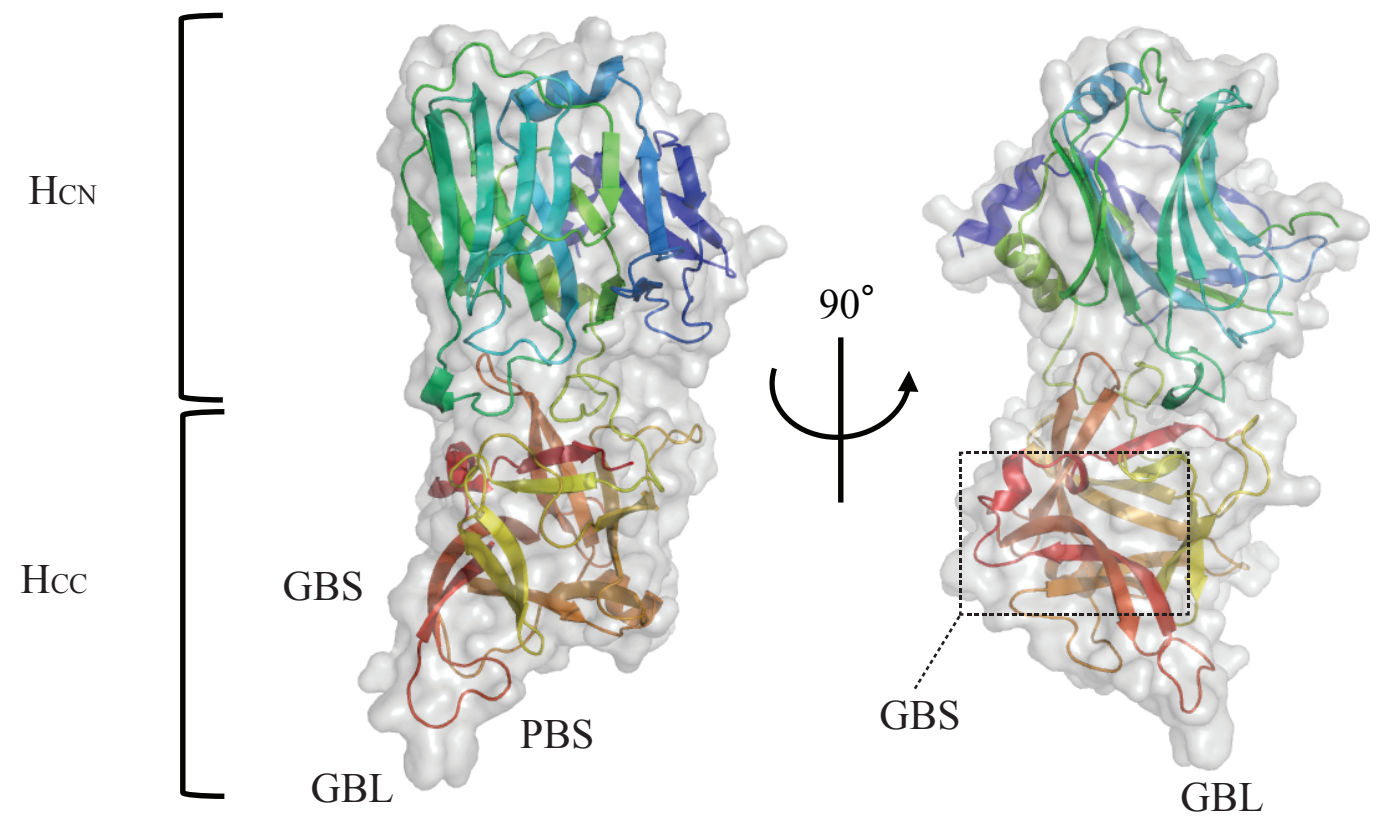

Figure 1B

Figure 1C
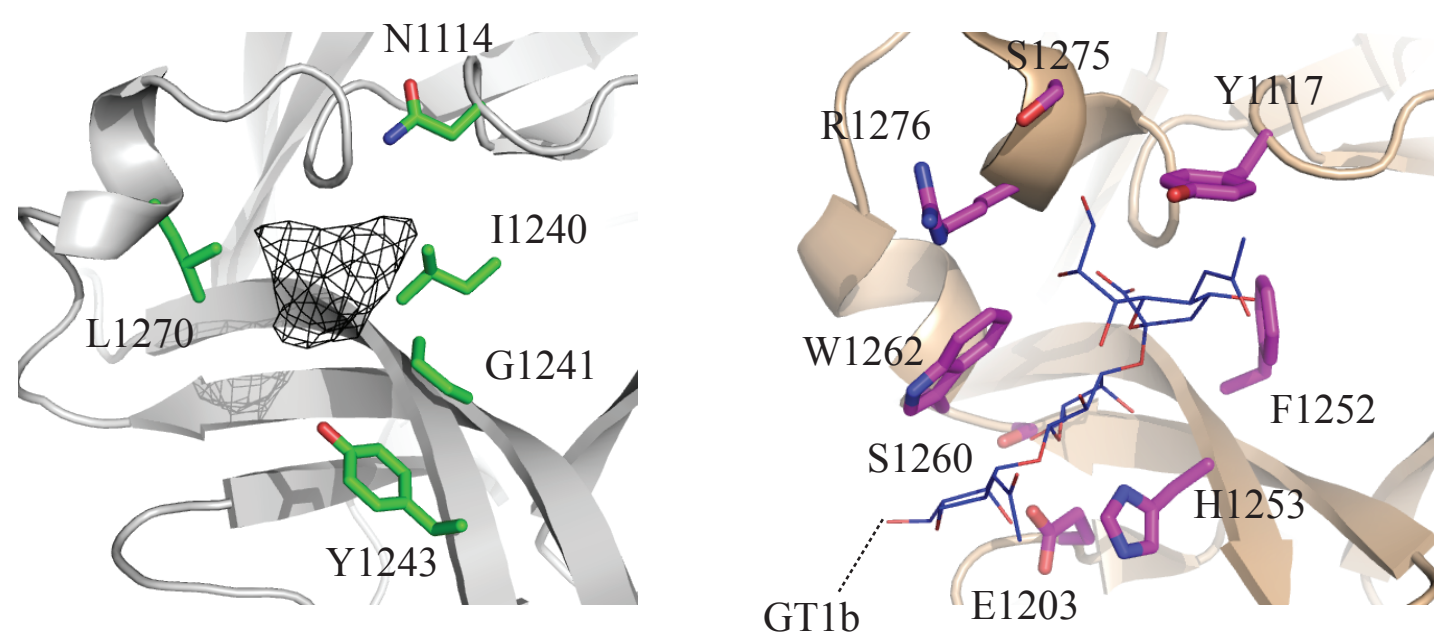

Figure 1D Superposition of BoNT/A_Hc, BoNT/B_Hc and OFD05Hc

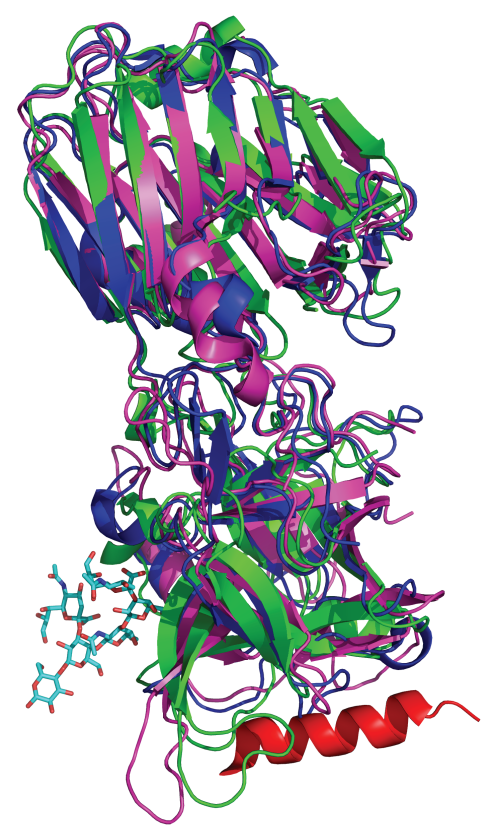

Green: OFD05Hc

Blue: BoNT/A_Hc + GT1b

(PDB: 2VU9)

Magenta: BoNT/B_Hc + Syt-II

(PDB: 2NM1) 
Figure 2A GM1a

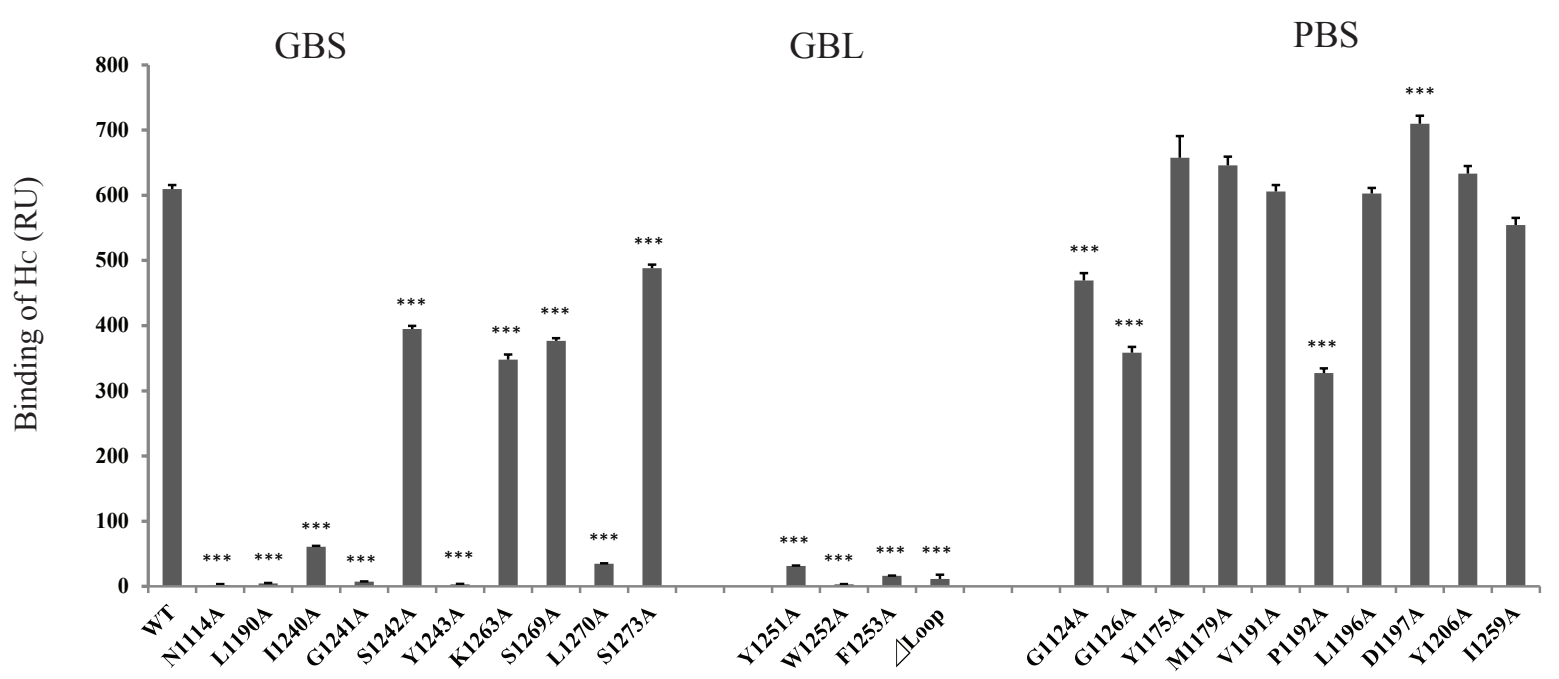

Figure 2B GD1a

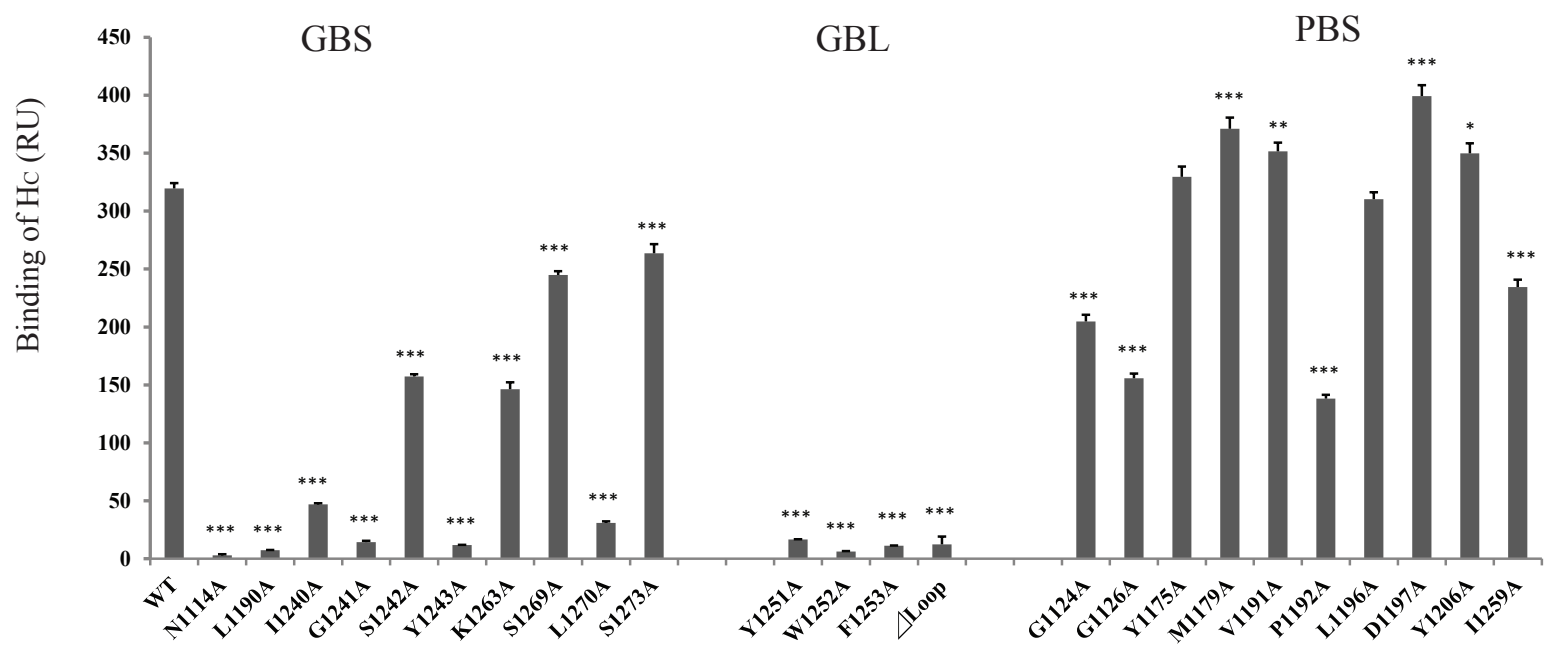

Figure 2C GQ1b

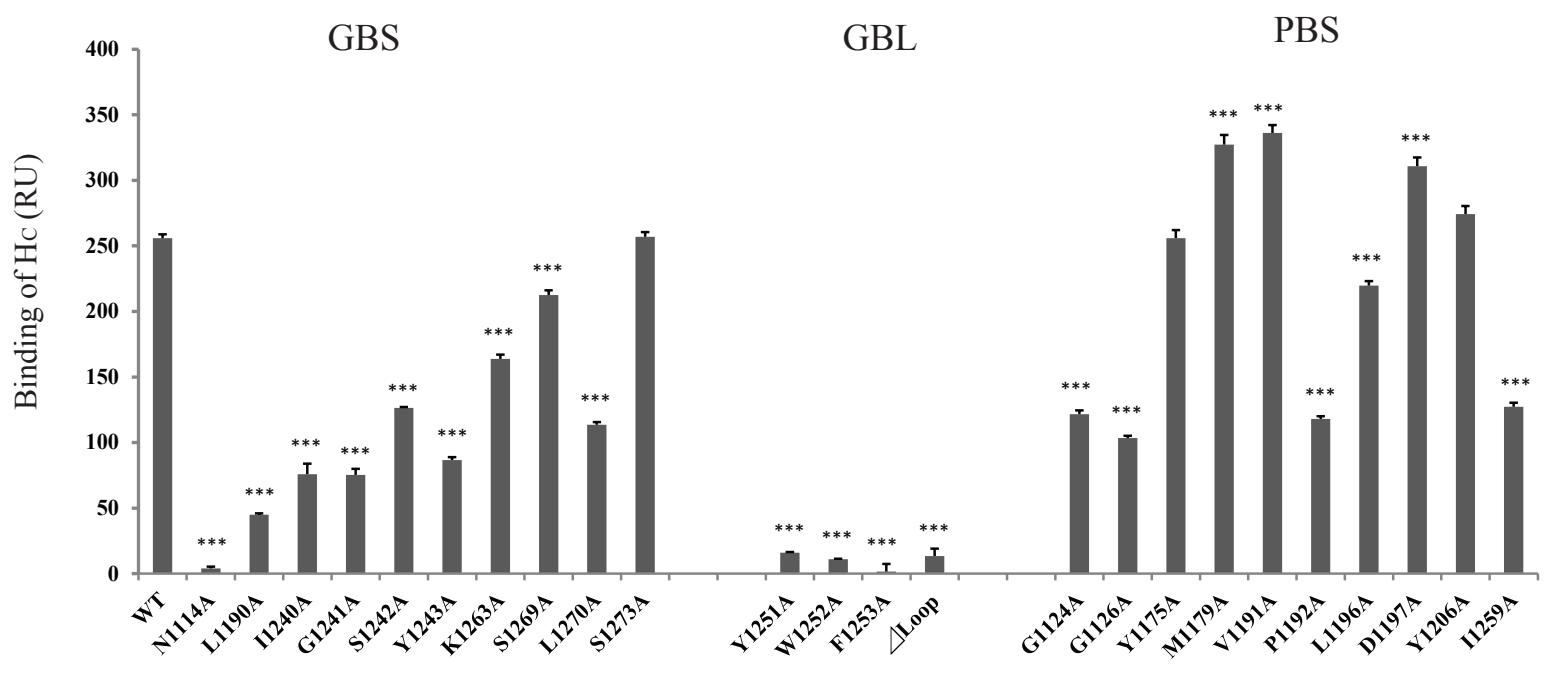




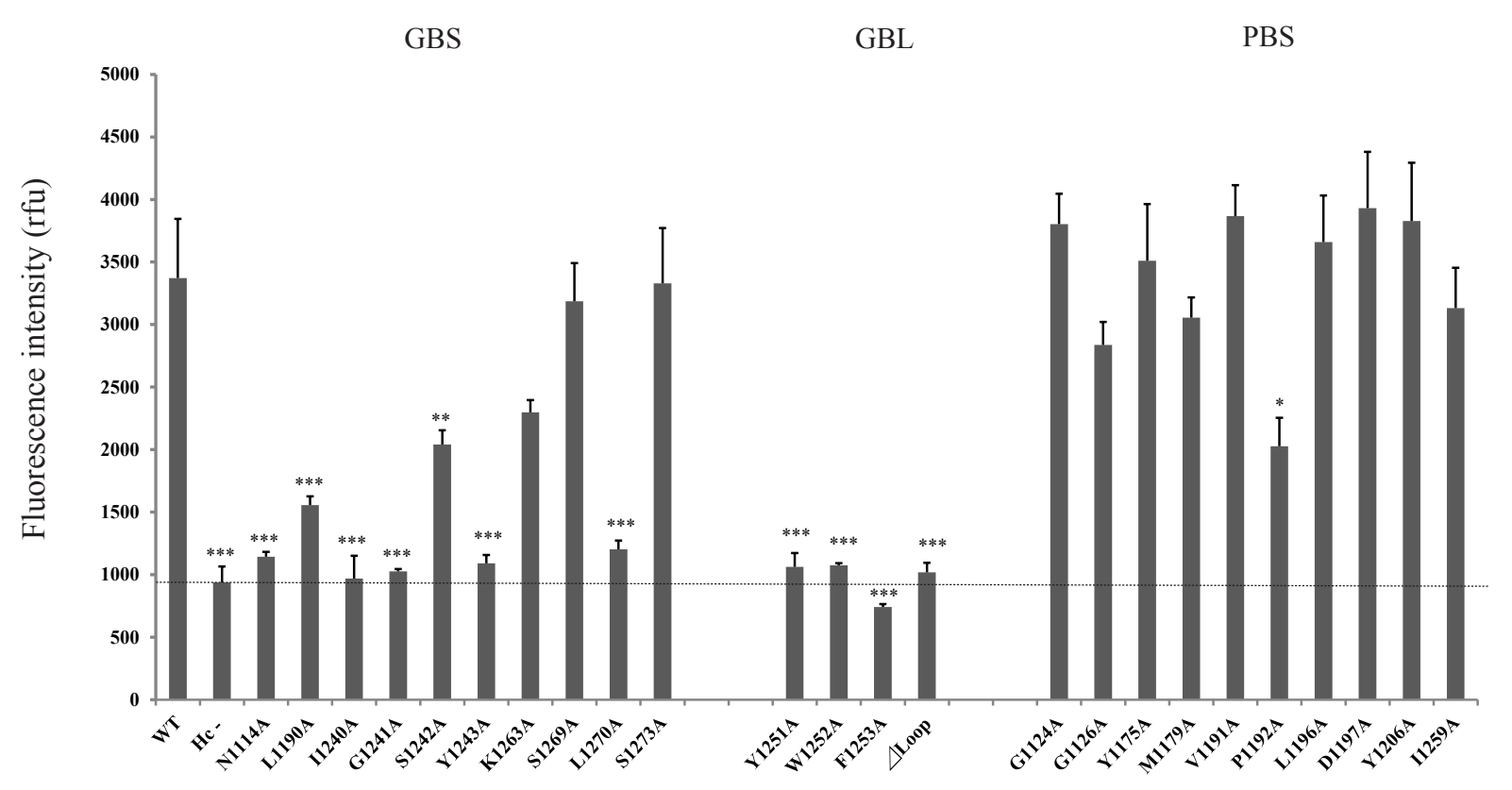


Supplementary figure 1 . OFD05Hc mutant candidates

\section{A. GBS}

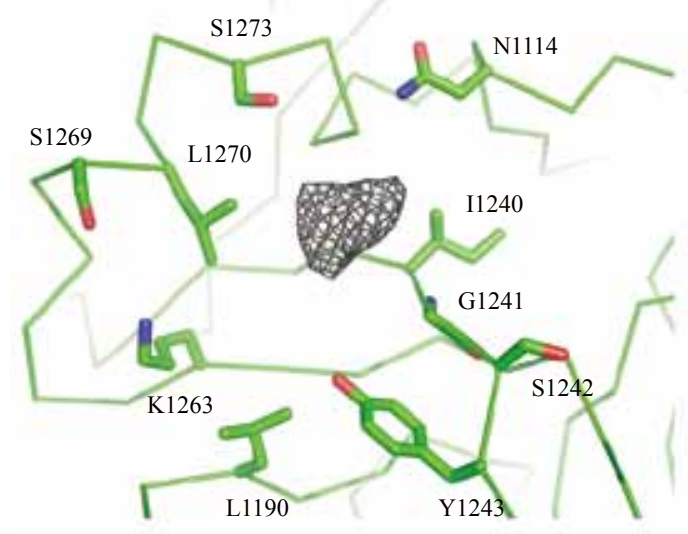

B. GBL

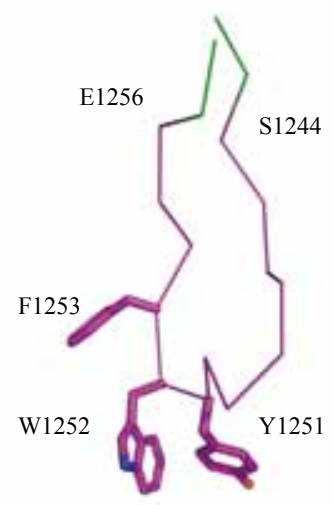

C. PBS

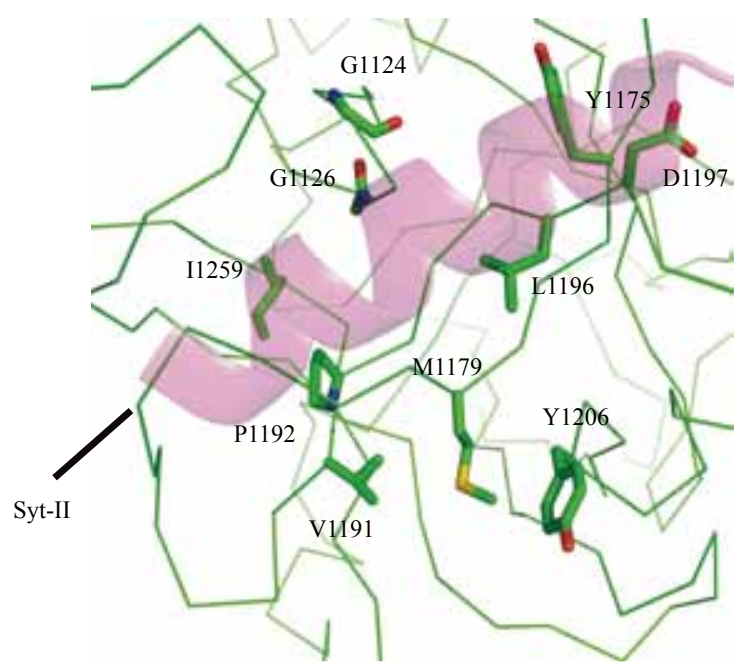


Supplemetary figure 2. Superposition of GBS of BoNT/A and OFD05

A. BoNT/A_HC + GT1b

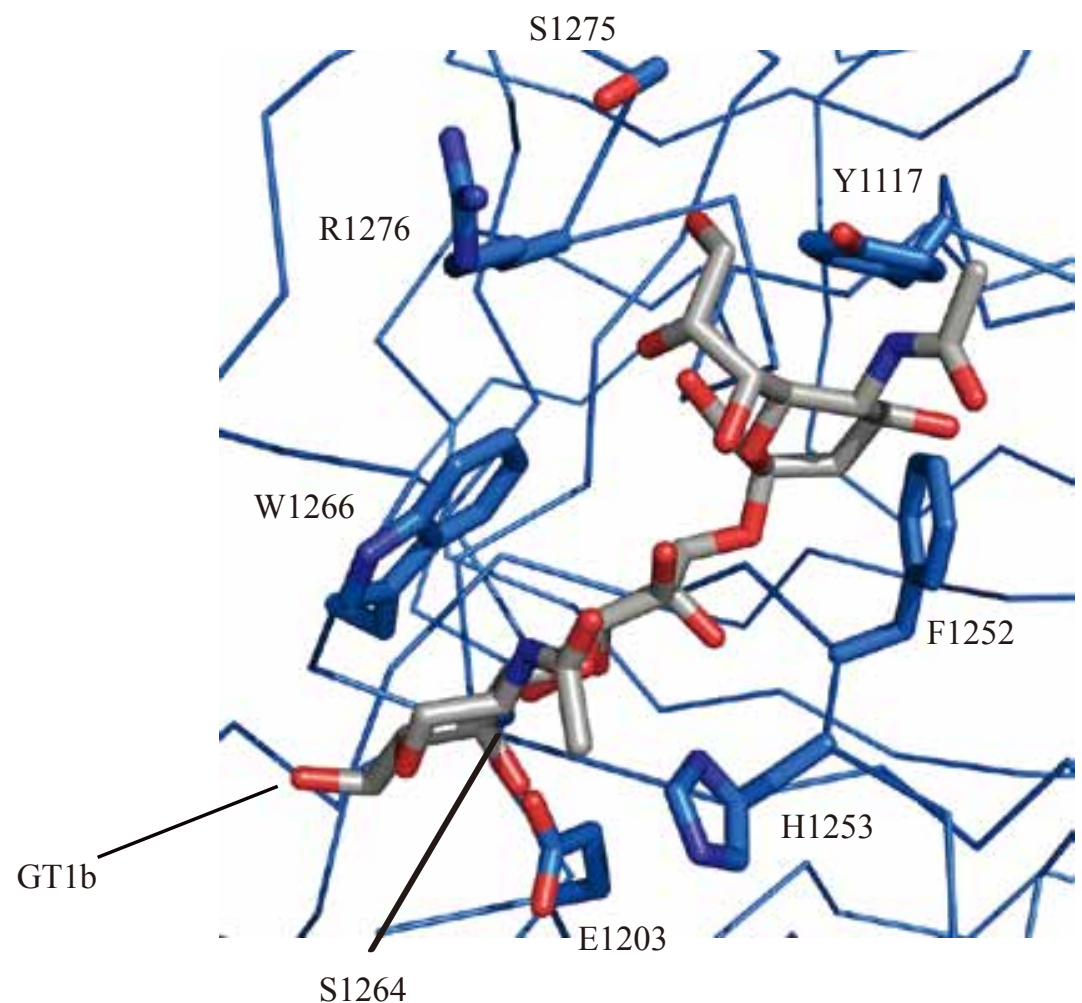

B. OFD05Hc + 3'-sialyllactose

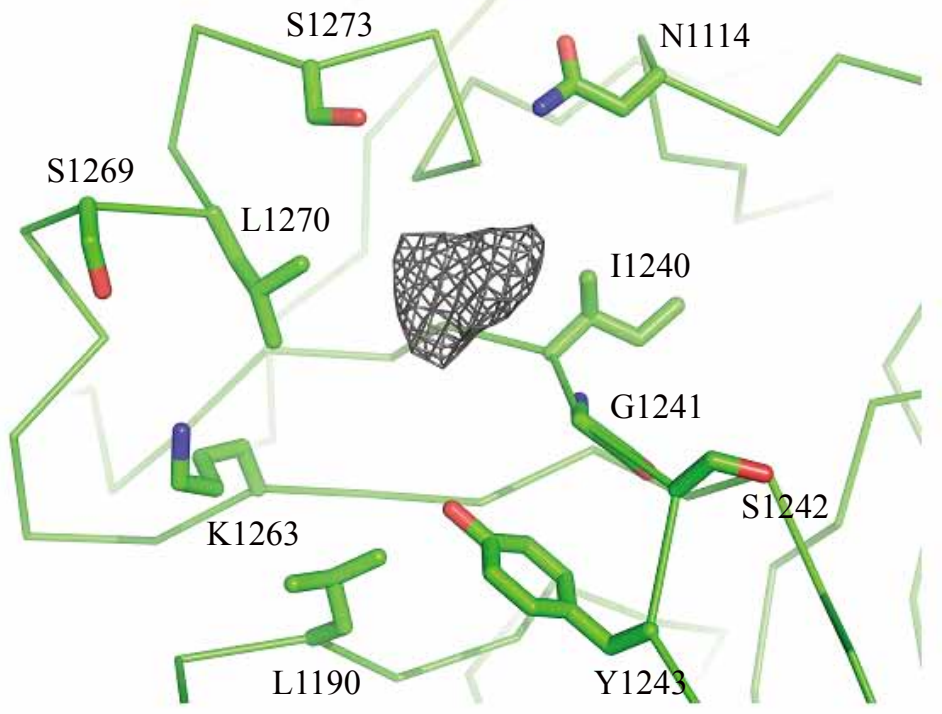


Supplementary figure 3. Superposition at PBS of BoNT/B and OFD05

A. BoNT/B_Hc + Syt-II

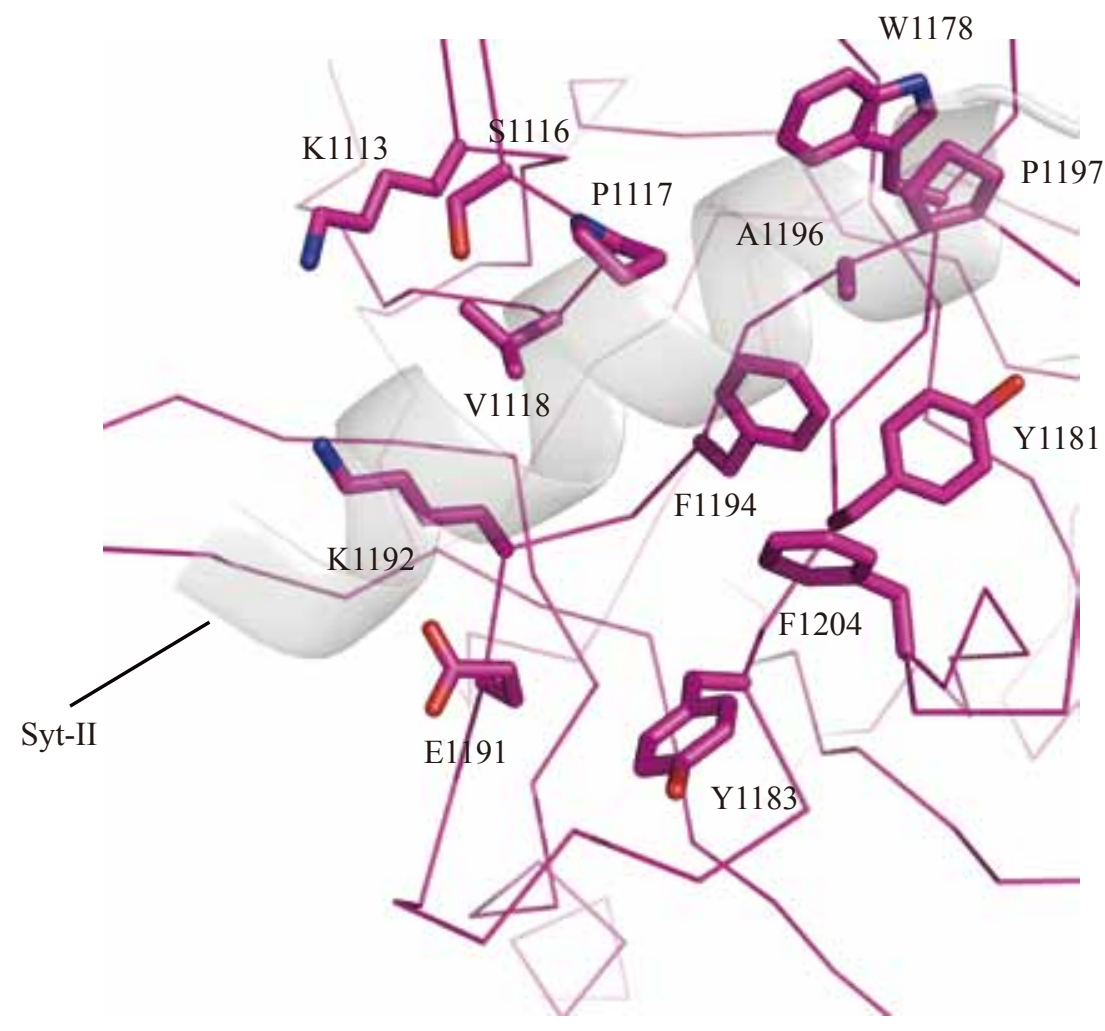

B. OFD05HC

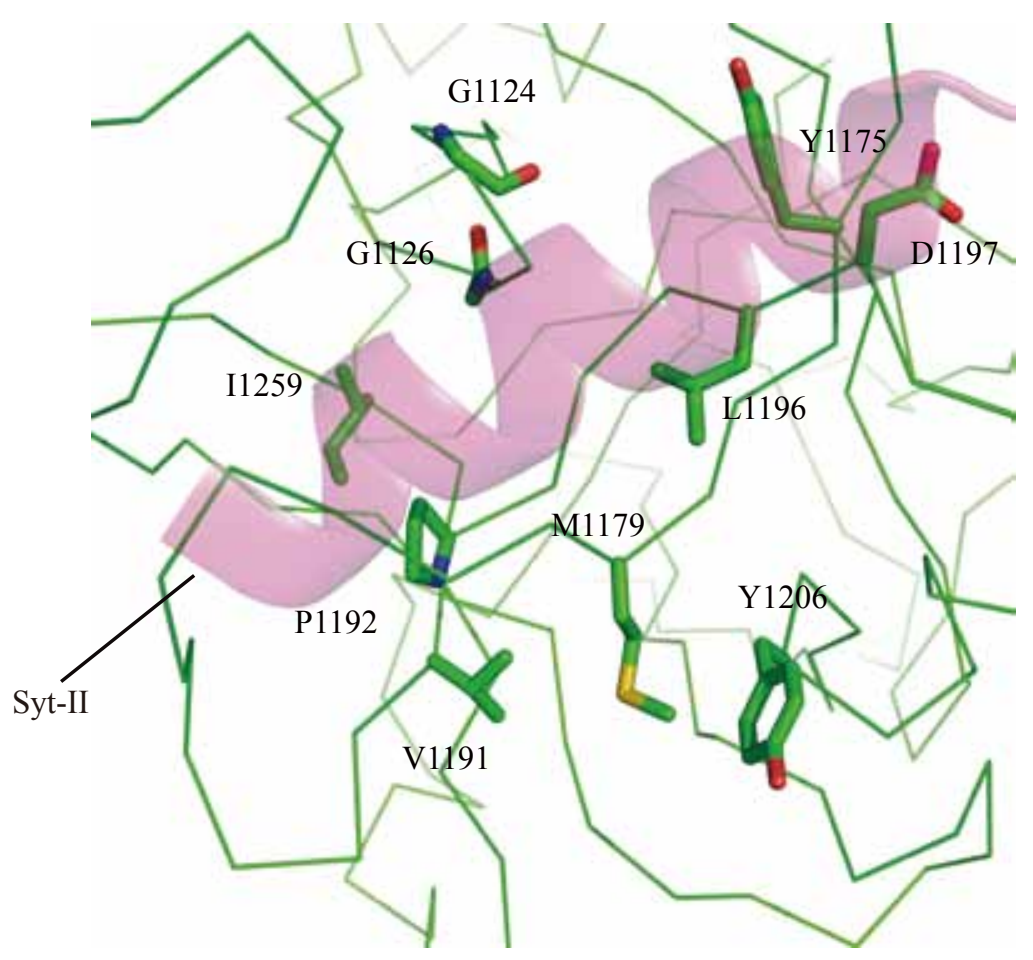


Supplementary figure 1. Mutated residues of $\mathrm{OFDO5H}_{\mathrm{C}}$ located around the GBS (A), GBL (B), and PBS (C). (A) Substituted residues located around the GBS including five residues adjacent to the ambiguous electron density and five candidates from superposition with the $\mathrm{H}_{\mathrm{C}}$ of BoNT/A are shown as sticks. The Fo\#c map derived from the 3'-sialyllactose is also shown. (B) Mutated residues located in the GBL. Three residues replaced by alanine are shown as sticks, and the region replaced by a linker (S1244\#1256) is shown as pink ribbons. (C). Mutated residues located around the PBS are shown as sticks. A cartoon model of Syt-II obtained by superposing BoNT/B\#\# Syt-II complex onto OFD05H $\mathrm{H}_{\mathrm{C}}$ is also shown.

Supplementary figure 2. Superposition of BoNT/A_H $H_{C}$ and $\mathrm{OFD05H}_{C}$ at GBS. Eight crucial residues for BoNT/A and GT1b recognition are shown (A). Structurally corresponding residues in OFD05 are shown (B).

Supplementary figure 3. Superposition of BoNT/B_H $\mathrm{H}_{C}$ and $\mathrm{OFD05H}_{C}$ at PBS. Thirteen crucial residues for BoNT/B and Syt-II recognition are shown. Syt-II is shown as transparent ribbon model in both BoNT/B and OFD05 model. 